\title{
Las personas voluntarias \\ en los grupos interactivos
}
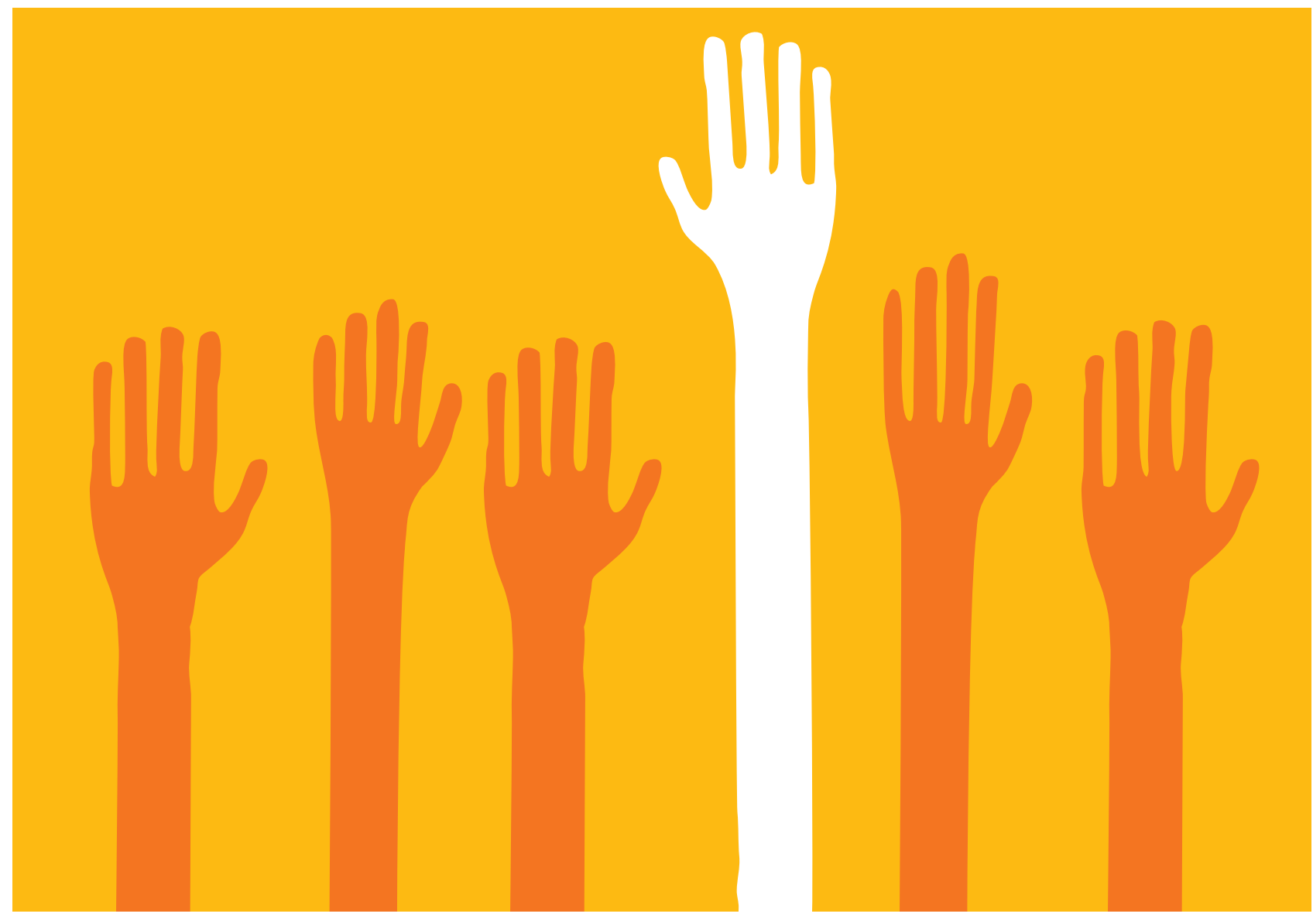

En este trabajo presentaremos de manera teórica y práctica el papel que tiene que realizar una persona voluntaria en la actuación educativa de éxito conocida como grupos interactivos. Para ello nos apoyamos en las aportaciones teóricas de algunos de los

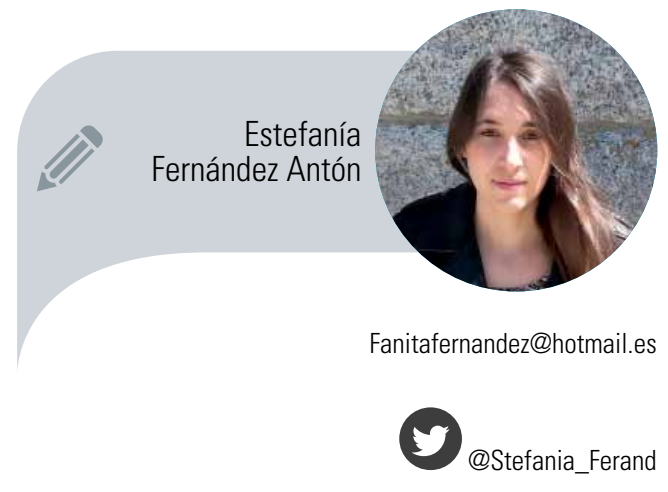
autores más significativos sobre la temática y en nuestra experiencia como investigadores participantes en una comunidad de aprendizaje. 
Imagen 1. Comparación entre la escuela tradicional y las comunidades de aprendizaje

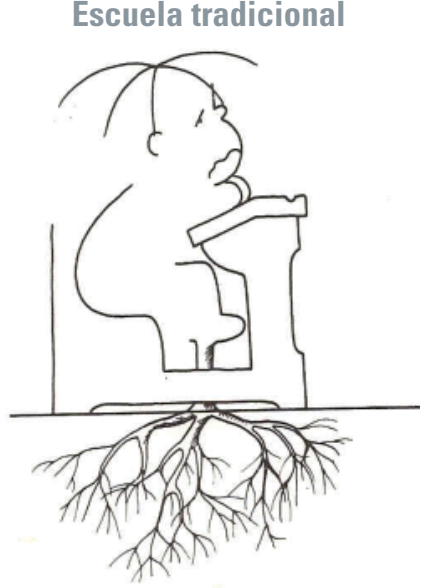

Fuente: colección de imágenes de Tonucci

\section{Comunidades de Aprendizaje}

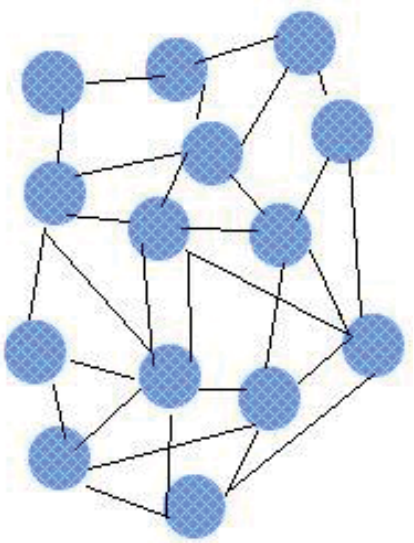

Fuente: página web oficial de comunidades de aprendizaje (http://utopiadream.info/ca/)
Los grupos interaclivos son una intervención

educaliva de éxito que permile que todos los alumnos

adquieran conocimientos académicos y sociales de

las diferentes áreas de conocimiento del currículum

establecido para cada etapa educaliva

\section{El papel de los agentes educativos en las comunidades de aprendizaje}

\section{El papel de los agentes educativos}

- El alumnado: ayuda a sus compañeros.

- El voluntariado: coordina la actividad con la ayuda del docente.

- El responsable de aula: programa las actividades y se asegura del buen funcionamiento de los grupos interactivos.

\section{Descripción de los grupos interactivos}

Antes de pasar a describir el significado de los grupos interactivos, me gustaría señalar que el objetivo es mostrar el papel que he llevado a cabo como voluntaria en una comunidad de aprendizaje, y más específicamente, en la actuación educativa de éxito denominada "grupos interactivos".

Los grupos interactivos son una intervención educativa de éxito que permite que todos los alumnos (indistintamente de su género, cultura, capa- cidad de adquirir conocimientos, grupos social de referencia, etc.) adquieran conocimientos académicos y sociales de las diferentes áreas de conocimiento del currículum establecido para cada etapa educativa.

Una actuación educativa de éxito tiene como característica principal la universalidad de su implantación en diferentes contextos culturales, geográficos y educativos. A diferencia de las buenas prácticas que funcionan en un determinado contexto.

Los grupos interactivos están implantados en centros educativos de diferentes etapas educativas (Infantil, Primaria, Secundaria, etcétera). Suelen ser centros que funcionan como comunidades de aprendizaje, que son un proyecto cultural y social que tiene como objetivo conseguir una educación de calidad y superadora de desigualdades para todos los alumnos y alumnas de las diferentes instituciones educativas. Para lograr este objetivo, se abren las puertas de los centros educativos a todas las personas de la comunidad, que pueden ser familiares del alumnado, estudiantes de otros centros y de otros niveles educativos, personas del pueblo o del barrio. Estas personas se involucrarán en el aprendizaje de los estudiantes y en el suyo propio, participando en las actividades de aprendizaje, en las actividades de evaluación y en la toma de decisiones del centro. Así pues, es un proyecto alternativo a lo que se conoce como escuela tradicional; porque todas las personas interactúan con todas, como se puede ver en la imagen 1.

En ella, vemos cómo el alumnado no interactúa con nadie en la escuela tradicional; sin embargo, en las comunidades de aprendizaje, los círculos azules que representan a todas las personas de la comunidad están interactuando entre sí.

Las comunidades de aprendizaje tienen como base teórica el aprendizaje dialógico; en este tipo de enseñanza el alumnado, las personas de la comunidad y el profesorado aprenden aportando ideas argumentadas y respetando cada idea por el valor de los argumentos. No importa el nivel de conocimientos académicos de la persona que los realiza.

La organización de los grupos interactivos se concreta en el papel de tres agentes: el alumnado, el voluntariado y el responsable de aula:

1. Los alumnos y alumnas del aula se dividen en cuatro o cinco grupos de cinco a seis niños. La división de los estudiantes puede 
tener variaciones dependiendo del número de niños que haya en cada aula. Aparte de la división, otra cuestión clave es la rotación, ya que cada grupo de cuatro o cinco niños tienen que ir rotando cada veinte minutos por las diferentes agrupaciones en las que se encuentra cada voluntario coordinando la actividad. Esta rotación es necesaria para que los estudiantes aprendan más contenidos académicos y sociales en una misma sesión, ya que tienen que resolver varias tareas y contar con la ayuda de varias personas voluntarias.

2. El voluntariado está compuesto por todas las personas de la comunidad. Tal y como hemos señalado en el párrafo anterior, estas personas coordinan cada agrupación de estudiantes. Sus funciones son conseguir que ningún alumno se quede sin aportar ideas o sin realizar las tareas de cada agrupación. Para ello tiene que promover el apoyo mutuo entre los estudiantes a través del diálogo.

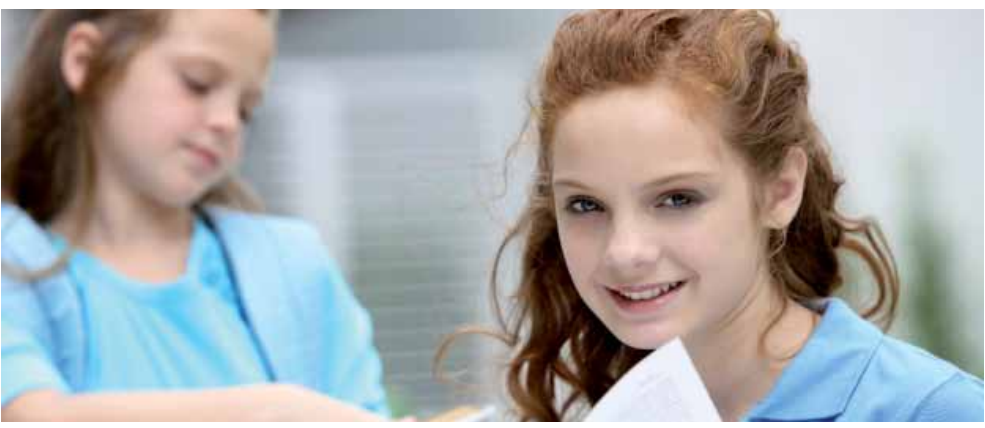

3. El papel de responsable de aula es llevado a cabo por un maestro o profesor de cada centro. Sus tareas son programar las actividades que tienen que solucionar cada agrupación de estudiantes y supervisar el funcionamiento de cada grupo desde fuera de cada agrupamiento. Las actividades tienen que estar relacionadas con un área de conocimiento y se puede trabajar en cada agrupación un contenido diferente (geometría, magnitudes, cálculo mental, etcétera).

En la tabla 1 aparecen las tareas de cada agente de manera más detallada.

Los grupos interactivos se organizan de esta manera, pero luego cada centro tiene sus particularidades. Por ejemplo, cada centro trabaja las áreas de conocimiento que consideren oportunas.

\section{Tabla 1. Funciones de los agentes educativos en los grupos interactivos}

\begin{tabular}{|l|l|l|l|}
\hline & Profesorado & Alumnado & Voluntariado \\
\hline \multirow{2}{*}{ Preparación } & $\begin{array}{l}\text { El profesorado planifica la sesión de grupos } \\
\text { interactivos. Prepara una actividad dife- } \\
\text { rente para cada pequeño grupo, que puede } \\
\text { realizarse en poco tiempo. }\end{array}$ & & $\begin{array}{l}\text { Familiares, profesorado jubilados, } \\
\text { estudiantes universitarios, profe- } \\
\text { sionales del barrio, etc., pueden } \\
\text { ser personas voluntarias en grupos } \\
\text { interactivos. }\end{array}$ \\
\hline \multirow{2}{*}{ Organización } & $\begin{array}{l}\text { Se coordina con el voluntariado para que } \\
\text { cada persona dinamice la actividad que } \\
\text { prefiera. Se decide conjuntamente. }\end{array}$ & $\begin{array}{l}\text { Conoce el funcionamiento de los grupos. } \\
\text { Se distribuye en grupos, tal y como se } \\
\text { haya acordado con el profesorado. Se } \\
\text { entusiasma con la participación del vo- }\end{array}$ & $\begin{array}{l}\text { El voluntario conoce la actividad que } \\
\text { va a dinamizar. Se coordina con la } \\
\text { maestra o maestro para llevarla a }\end{array}$ \\
\hline \multirow{2}{*}{ cabo con éxito. }
\end{tabular}

Fuente: página web oficial de comunidades de aprendizaje (http://utopiadream.info/ca/) 


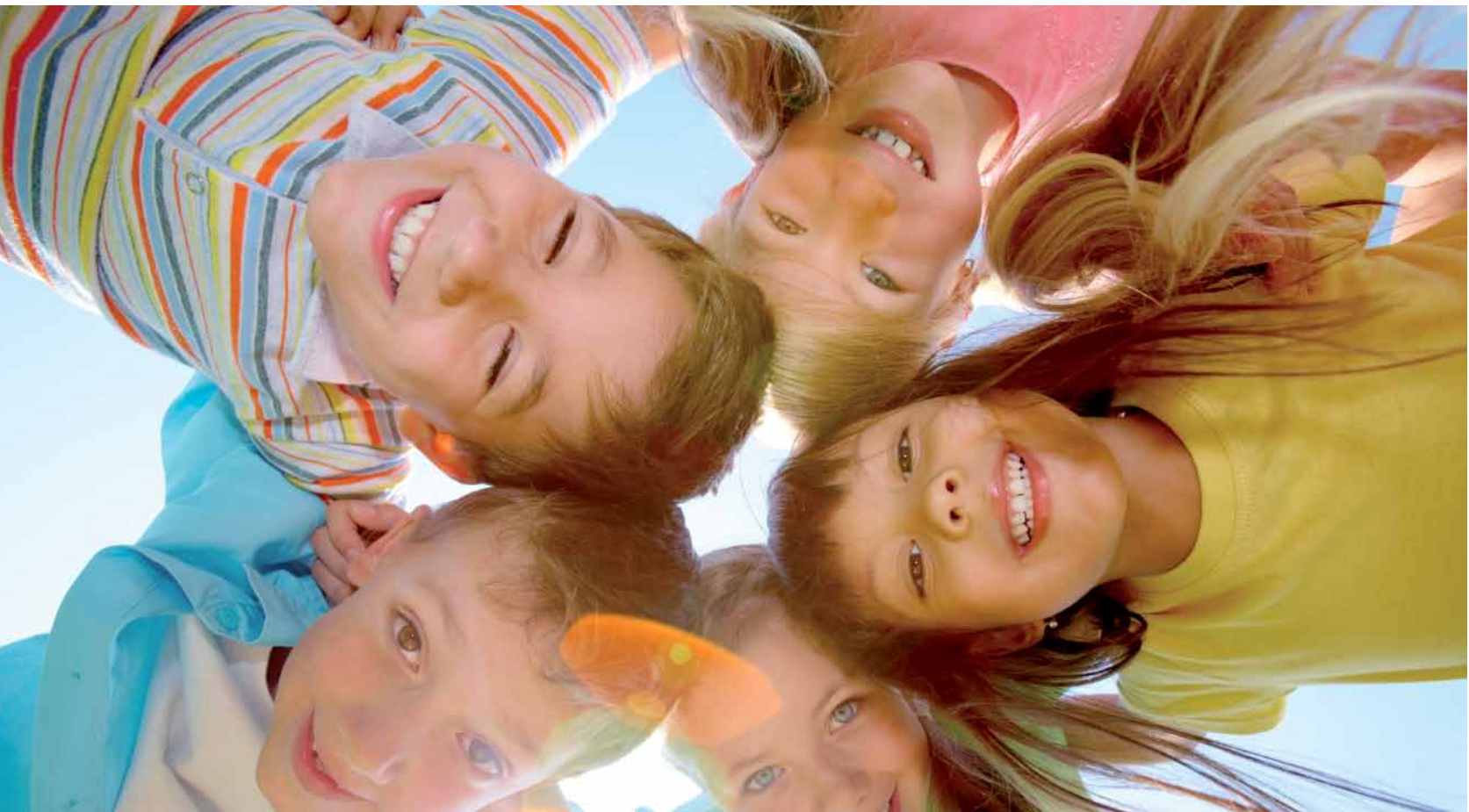

\section{Orra cuestión clave es la rolación, ya que cada grupo de cuatro o cinco niños lienen que ir rolondo cada veinte minutos por las \\ diferentes agrupaciones}

\section{ÁQORA DE PROFESORES}

En la actuación socioeducativa de éxito "grupos interactivos", el profesorado puede hacer uso de su imaginación para plantear distintos tipos de actividades académicas:

$\checkmark$ Actividades reflexivas: reflexionar sobre imágenes de temas de interés social (pobreza, exclusión social, absentismo escolar, etc.) y reflexionar sobre cortos educativos (Cuerdas, El Viaje de Said, etcétera).

$\checkmark$ Actividades más tradicionales: Tangram, puzles, laberintos, sopa de letras, sopa de números...

$\checkmark$ Actividades con el ordenador: investigación, actividades de gramática, de operaciones aritméticas, etc.

\ Cada actividad tenía las siguientes características: están conectadas a las áreas de conocimiento del currículum de etapa; son inclusivas; porque tienen en cuenta a todo el alumnado (independientemente de su ritmo de aprendizaje, cultura, género, etc.) y, después de cada actividad, los estudiantes con la ayuda de los docentes y del voluntariado reflexionan sobre el progreso social y académico de cada niño o niña.

Esta intervención de éxito fue desarrollada en el Centro Especial de Investigación en Teorías y Prácticas Superadoras de Desigualdades (CREA'). Y las aportaciones teóricas anteriores las hemos obtenido de diferentes documentos, como son: Aubert, Flecha, García, Flecha y Racionero (2010); Molina (2011); Ojala y Padrós (2012); Oliver y De Gràcia (2004); Oliver y Gatt (2010) y Racionero, García, Aubert y Puigvert (2009).

\section{Nuestra experiencia}

Como hemos señalado al principio del trabajo, nuestro objetivo es mostrar el papel que he desarrollado como persona voluntaria en una comunidad de aprendizaje.

En la comunidad de aprendizaje, participaba junto con otros voluntarios una vez a la semana en los grupos interactivos de diferentes áreas de conocimiento.

Cuando llegábamos al centro, entrabamos al aula donde se realizaban las agrupaciones interactivas, y ayudábamos al resto de voluntarios a organizar el aula; normalmente hacíamos cuatro agrupaciones de mesas para cinco alumnos.

Una vez que el aula estaba preparada para empezar con la sesión de los grupos interactivos, los voluntarios se ponían de acuerdo mediante el diálogo para coordinar las mesas de las actividades.

En todas las sesiones, los alumnos y alumnas debatían y dialogaban para solucionar las tareas académicas. Al principio, las personas voluntarias teníamos que mediar para que el alumnado llegase

1 http://creaub.info/es/ 


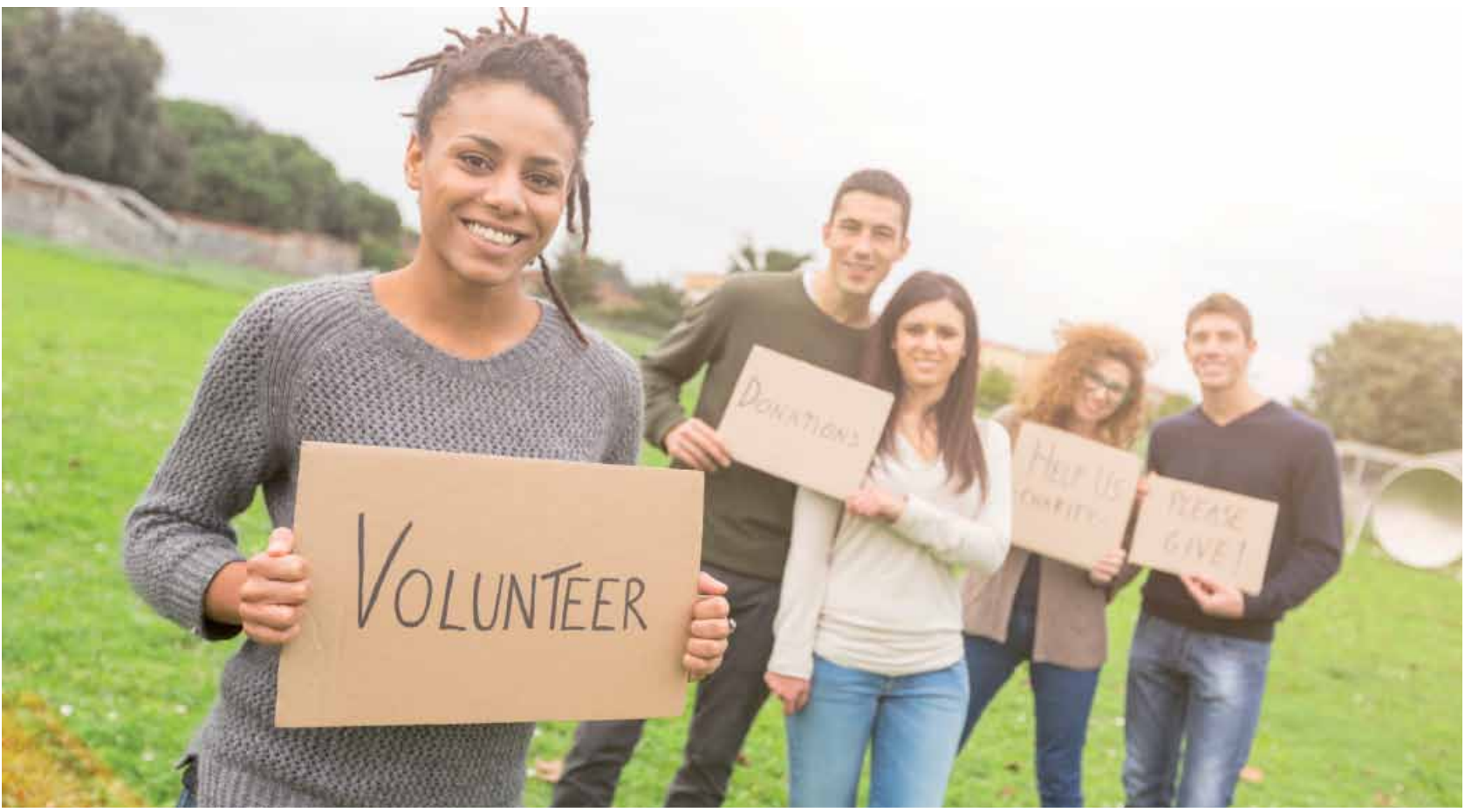

a entendimientos; sin embargo, a medida que los estudiantes participaban en más sesiones interactivas, más capacidades comunicativas y colaborativas iban desarrollando.

Nosotros también mejoramos nuestras habilidades para coordinar cada grupo, ya que al principio nos costaba mucho promover la colaboración entre los estudiantes, pues pensábamos que al ser adultos nuestro papel tenía que centrarse principalmente en transmitir conocimientos. También nos costaba promover el diálogo entre estudiantes para que ellos resolvieran las tareas académicas de cada mesa reflexionando. Nosotros pensábamos que se tenían que dar las respuestas entre ellos, pero las personas de la comunidad nos ayudaron a adquirir habilidades que nos permitirían participar en las agrupaciones interactivas de manera adecuada.

Como ya hemos señalado en el apartado anterior, los alumnos y alumnas rotaban de actividad cada veinte minutos. Aparte de esta acción, también tenían que evaluar los comportamientos de los compañeros en las sesiones. Para este fin, tenían que dar ideas sobre cada alumno y apuntarlas en una hoja de evaluación. El niño que apuntaba las ideas era el portavoz del equipo, que era elegido por todos los compañeros. En las actividades de evaluación, nosotros como voluntarios no podíamos dar ninguna idea porque era una acción propia de los estudiantes.

Al final de cada sesión, todas las personas voluntarias nos reuníamos con los niños y niñas. Este encuentro servía para mostrar al alumnado las actitudes que tenían que mejorar o las que tenían que desarrollar. Para presentar esta información al alumnado, cada persona voluntaria tenía un turno de intervención.

Destacar que las principales cuestiones que tenemos que plantearnos en relación a la hora de proponernos una actividad mediante la metodología de los grupos interactivos serían: ¿tienen relación con las áreas de conocimiento del currículum de etapa?, ¿están pensadas para todo el alumnado del aula? y ¿hay un momento de reflexión final para valorar el desarrollo social y

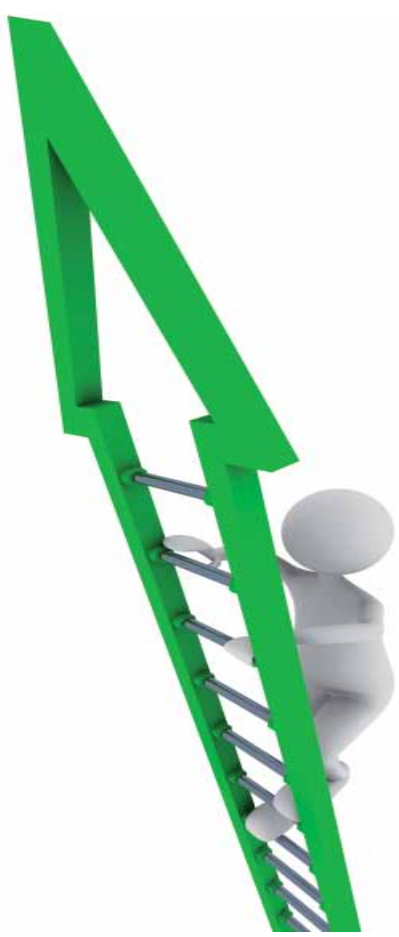




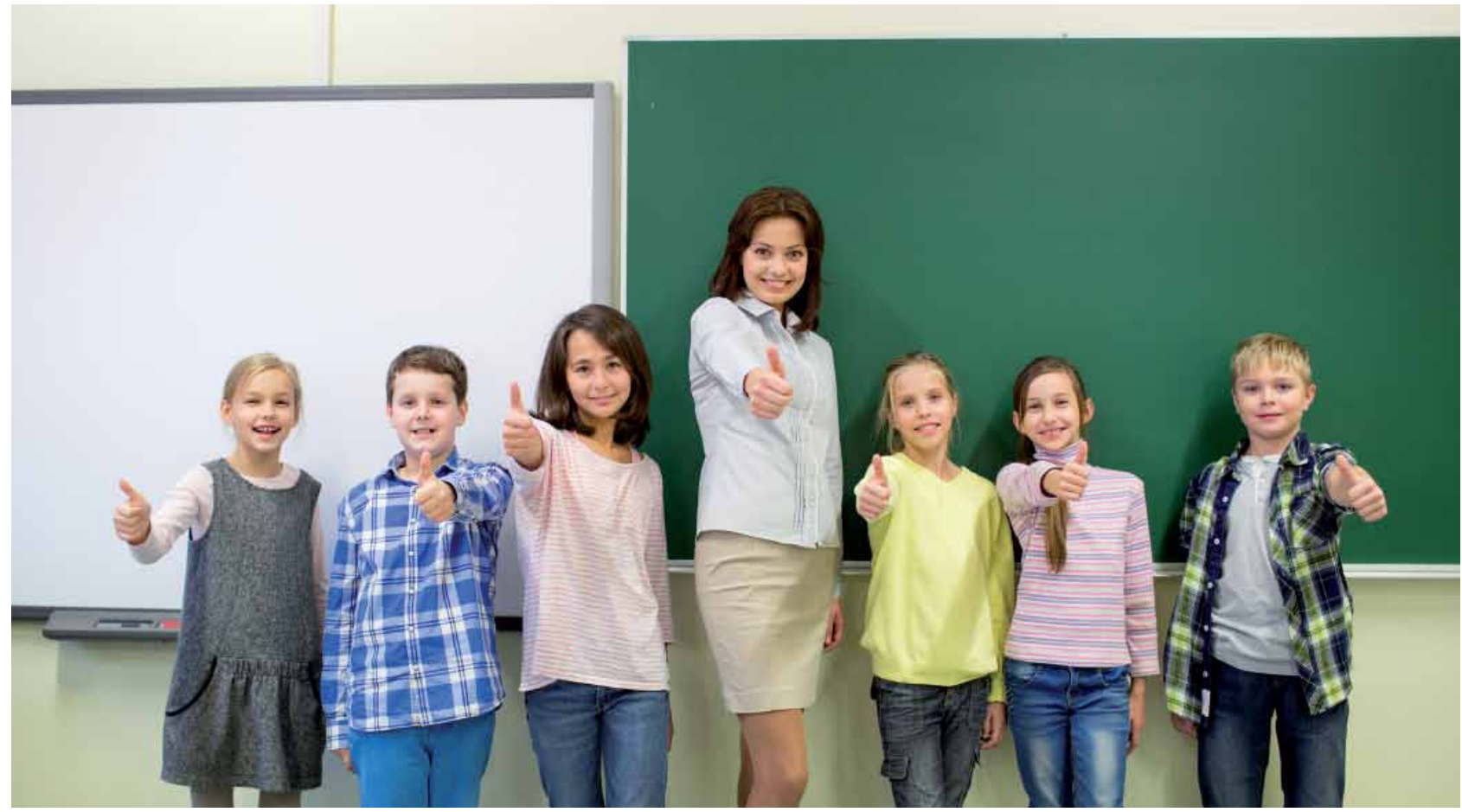

\section{blbLografía comentada}

Aubert, A., Flecha, A., García, C., Flecha, R., y Racionero, S. (2010). Aprendizaje dialógico en la sociedad de la información. Barcelona: Hipatia.

Mouna, S. (2011). Los grupos interactivos: una práctica de las Comunidades de Aprendizaje para la inclusión del alumnado con discapacidad (Tesis doctoral). Recuperada de Tesis Doctorales en Red en http://hdl.handle.net/2445/43112

OJala, M., y PAdrós, Ma. (2012). "Actuaciones de éxito, universales y transferibles". Cuadernos de Pedagogía, 429, pp. 18-19.

Oliver, E., y De Gràcia, S. (2004). Grupos interactivos en Secundaria. Cuadernos de Pedagogía, 341, pp. 70-72.

Oliver, E., y GatT, S. (2010). "De los actos comunicativos de poder a los actos comunicativos dialógicos en las aulas organizadas en grupos interactivos". Signos, 43 (2), pp. 279-294.

Prados, Ma . M., y Aguilera, A. (2013). "Los alumnos y alumnas de la Universidad de Sevilla como voluntarios en Comunidades de Aprendizaje". Revista Andalucía Educativa.

Racionero, S., García, R., Aubert, A., y Puigvert, L. (2009). "Los modelos sociales de enseñanza: Los grupos interactivos". Competencias Básicas y Modelos de Enseñanza. Escuela, 4.

\section{Aprendizaje dialógico, Comunidades de Aprendizaje, grupos interactivos, innovación educativa.}

Este artículo fue solicitado por PADRES y MAESTROS en diciembre de 2014, revisado y aceptado en marzo de 2015. académico que está ofreciendo cada actividad al alumnado?

Como conclusión, comentar que las actividades indicadas con anterioridad en la ágora de profesores las hemos puesto en práctica en la comunidad de aprendizaje donde realicé esta experiencia como voluntaria. Además, las actividades estaban conectadas a las áreas de conocimiento del currículum de etapa y eran inclusivas porque tenían en cuenta a todo el alumnado (independientemente de su ritmo de aprendizaje, cultura, género, etcétera). Y, después del desarrollo de todas las actividades, los estudiantes con la ayuda del voluntariado reflexionaban sobre el progreso social y académico de cada niño. Espero que esta experiencia resulte de interés, para todos aquellos maestros y profesores interesados en esta metodología, tanto como lo ha sido para mí en mi formación como futura docente •

\section{OR DARA SABER MÁS}

LunA, F. (2007a). "Aprender en grupos interactivos". Cuadernos de Pedagogía, 368, pp. 18-23.

Odina, M., Buitago, M., y Alcalde, A. I. (2006). "Los grupos interactivos". En F. López (Dir.), Transformando la escuela: Comunidades de Aprendizaje (pp. 97-102). Barcelona: Graó, pp. 97-102.

Ortega, S., y Puigdelívol, I. (2006). "Incluir es sumar. Comunidades de Aprendizaje como modelo de escuela inclusiva". En F. López (Dir.), Transformando la escuela: Comunidades de Aprendizaje (pp. 35-42). Barcelona: Graó, pp. 35-42. 